\title{
CD4+CD25+ Tregs control the TRAIL- dependent cytotoxicity of tumor-infiltrating DCs in rodent models of colon cancer
}

\author{
Stephan Roux,, ${ }^{1,2,3}$ Lionel Apetoh, ${ }^{1,2,3}$ Fanny Chalmin, ${ }^{4}$ Sylvain Ladoire, ${ }^{4,5}$ Grégoire Mignot, ${ }^{1,2,3}$ \\ Pierre-Emmanuel Puig, ${ }^{4}$ Gregoire Lauvau, ${ }^{6}$ Laurence Zitvogel, ${ }^{1,2,3}$ François Martin, ${ }^{4}$ \\ Bruno Chauffert, ${ }^{4,5}$ Hideo Yagita, ${ }^{7}$ Eric Solary, ${ }^{4}$ and François Ghiringhelli ${ }^{1,4,5}$ \\ 1INSERM U805, Villejuif, France. ${ }^{2}$ Institut Gustave Roussy, Villejuif, France. ${ }^{3}$ Faculté Paris Sud — Université Paris 11, Kremlin-Bicêtre, France.
4INSERM UMR 866, Faculté de Médecine, Dijon, France. ${ }^{5}$ Centre Georges-François Leclerc, Dijon, France. ${ }^{6}$ Groupe Avenir, INSERM E-344,
Université de Nice Sophia Antipolis, Valbonne, France. ${ }^{2}$ Department of Immunology, Juntendo University School of Medicine, Tokyo, Japan.
}

Tumors that progress do so via their ability to escape the antitumor immune response through several mechanisms, including developing ways to induce the differentiation and/or recruitment of $\mathrm{CD}^{+} \mathrm{CD} 25^{+} \mathrm{Tregs}$. The Tregs, in turn, inhibit the cytotoxic function of T cells and NK cells, but whether they have an effect on the cytotoxic function of tumor-infiltrating DCs (TIDCs) has not been determined. Here we have shown, in 2 rodent models of colon cancer, that $\mathrm{CD}^{+} \mathrm{CD}^{+} 5^{+}$Tregs inhibit the ability of CD11b ${ }^{+} \mathrm{TIDCs}$ to mediate TNF-related apoptosis-inducing ligand-induced (TRAIL-induced) tumor cell death. In both models of cancer, combination treatment with Mycobacterium bovis Bacillus Calmette-Guérin (BCG), which activates the innate immune system via TLR2, TLR4, and TLR9, and cyclophosphamide (CTX), which depletes Tregs, eradicated the tumors. Further analysis revealed that the treatment led to a marked increase in the number of CD11 ${ }^{+}$TIDCs that $^{2}$ killed the tumor cells via a TRAIL-dependent mechanism. Furthermore, acquisition of TRAIL expression by the CD11b ${ }^{+}$TIDCs was induced by BCG and dependent on signaling through TLR2, TLR4, and TLR9. In vivo transfer of Tregs abrogated the ability of BCG to induce CD11b ${ }^{+}$TIDCs to express TRAIL and thereby nullified the efficacy of the CTX-BCG treatment. Our data have therefore delineated what we believe to be a novel mechanism by which Tregs inhibit the antitumor immune response.

\section{Introduction}

Tumor stroma is richly invaded by host cells, which include tumorinfiltrating DCs (TIDCs) identified in virtually all human cancers (1-7) and experimental tumor models (8-12). Immunological functions of TIDCs remain only partly understood (13). Most reports claim that these cells are immature, thus unable to induce an efficient anti-tumor immune response, and inhibition of DC maturation and function is thought to be one of the mechanisms through which tumors evade the immune system $(3,9,14,15)$. Additionally, certain tumors mediate immunosubversion by promoting the differentiation of TGF- $\beta$-secreting DCs that expand $\mathrm{CD} 4^{+} \mathrm{CD} 25^{+}$ Tregs (16) or by directly recruiting Tregs through chemokine production such as CCL22 (17). In turn, Tregs inhibit classical cytotoxic cells such as T and NK cells (18-20) and contribute to tumor escape and poor survival. Nevertheless, the ability of Tregs to control the killing capacities of DCs in tumors was never investigated.

Several therapeutic strategies were proposed to attempt to restore the ability of DCs to mediate an efficient antitumor immune response. For example, the Mycobacterium bovis Bacillus Calmette-Guérin-cell-wall skeleton (BCG-CWS) was shown to act as a potent inducer of ex vivo DC maturation via its TLR agonist

Nonstandard abbreviations used: BCG, Bacillus Calmette-Guérin; BM-DC, BMderived DC; CTX, cyclophosphamide; IKDC, IFN- $\gamma$-producing killer DC; L-NMMA, $\mathrm{N}$-monomethyl-L-arginine; MHC-II, MHC class II; Mo-DC, monocyte-derived DC; Tconv, conventional CD $4^{+} \mathrm{CD} 25^{-} \mathrm{T}$ cell; TIDC, tumor-infiltrating DC; TRAIL, TNF-related apoptosis-inducing ligand; Z-VAD-fmk, Z-valine-alanine-aspartatefluoromethyl ketone.

Conflict of interest: The authors have declared that no conflict of interest exists. Citation for this article: J. Clin. Invest. 118:3751-3761 (2008). doi:10.1172/JCI35890. activity (21). Moreover, preventive administration of BCG could delay tumor growth in vivo in a TLR2- and TLR4-dependent manner (22). Furthermore, TLR triggering together with IL-10 neutralization reverted tumor-induced TIDC paralysis and elicited an efficient antitumor immune response (10). A combination of IL-2 and Imatinib mesylate expands a subtype of tumor-infiltrating cells with NK functions and DC markers that kill tumor cells through TNF-related apoptosis-inducing ligand (TRAIL) and control tumor growth $(23,24)$. Thus, redirecting TIDCs from a protolerant to a pro-Th1 state or toward cytotoxic function might be an efficient strategy in tumor immunotherapy. However, mechanisms controlling the switch from tolerogenic to immunogenic TIDCs remain elusive.

In the present study, we demonstrate in 2 models of colon carcinoma in rodents that the combination of 2 treatments used in the clinic, low-dose cyclophosphamide (CTX) and M. bovis BCG, a mycobacterium that activates innate components of the immune system through TLR2, TLR4, and TLR9 $(25,26)$, induced an accumulation of cytotoxic myeloid TIDCs that kill tumor cells through expression of TRAIL. Specifically, we report that Tregs control TRAIL acquisition on BCG-stimulated TIDCs and thereby compromise their in vitro and in vivo antitumor activity.

\section{Results}

Synergistic antitumor effects of CTX and BCG. The treatment, consisting of 1 systemic injection of CTX followed by 2 intratumoral injections of BCG, was tested in 2 models of established subcutaneous tumors (PROb in BD-IX rats and CT26 in BALB/c mice). When administered alone, CTX and BCG therapies demonstrated 
A

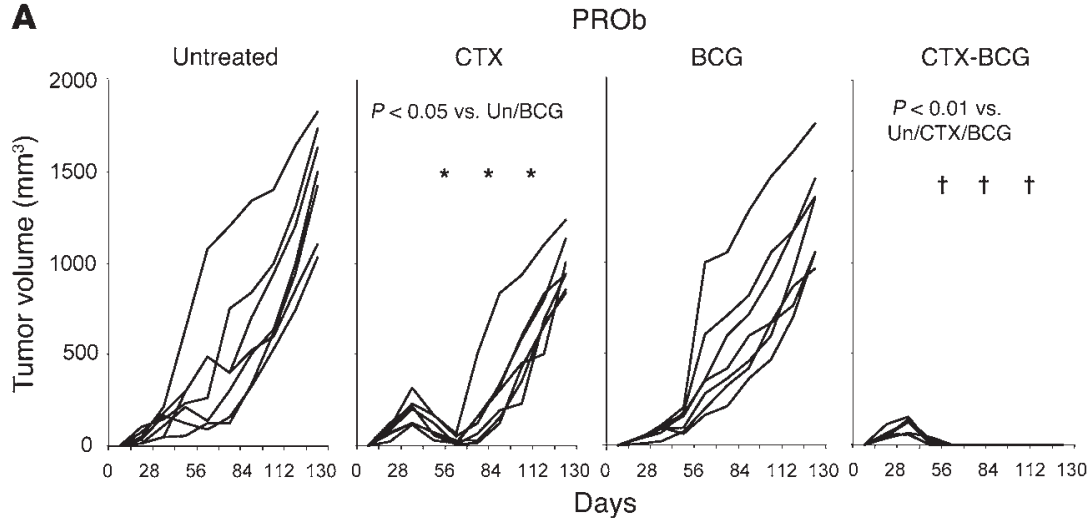

B

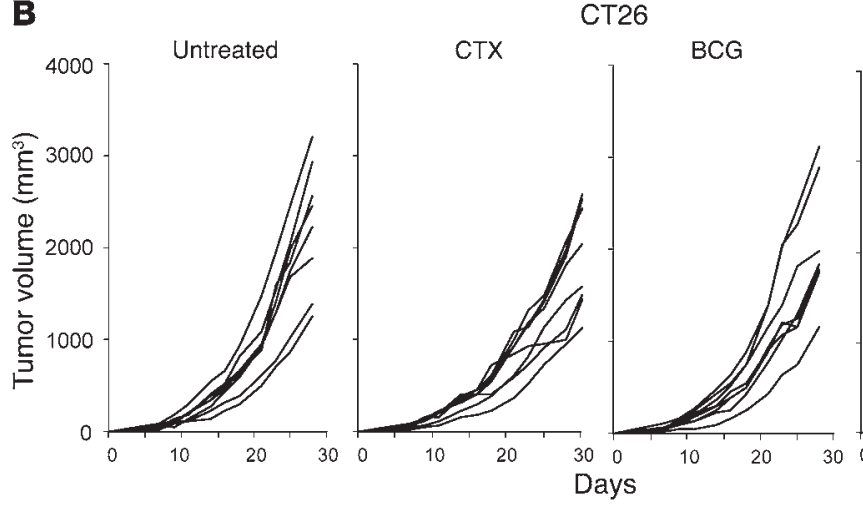

CTX-BCG

$P<0.01$ vs.

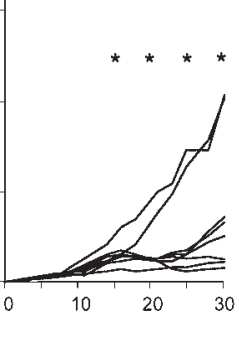
Un/CTX/BCG

\section{Figure 1}

Synergistic antitumor effect of CTX administration followed by intratumoral BCG injections in 2 tumor models. (A) Four groups of 7 wild-type BD-IX rats received a subcutaneous injection of $1 \times 10^{6}$ syngeneic PROb tumor cells. Rats received 1 i.p. injection of CTX $(30 \mathrm{mg} / \mathrm{kg})$ on day 28 after tumor cell injection, or 2 intratumoral injections of BCG $\left(8 \times 10^{5} \mathrm{CFU}\right)$ on day 35 and 42 , or both. Control group received saline injections. Statistical comparison of mean tumor volume of the control group and treated groups was performed every 28 days, beginning on day 56. (B) Four groups of 8 wild-type $B A L B / c$ mice received a subcutaneous injection of $5 \times 10^{5}$ syngeneic CT26 tumor cells. Mice received 1 i.p. injection of CTX $(100 \mathrm{mg} / \mathrm{kg}$ body weight) on day 7 after tumor cell injection, or 2 intratumoral injections of BCG $\left(8 \times 10^{4} \mathrm{CFU}\right)$ on day 9 and 14, or both. Untreated mice received saline injections. One experiment out of 3 is shown. Statistical comparison of mean tumor volume of the control group and treated groups was performed on days $15,20,25$, and $30 .{ }^{*} P<0.05$; $+P<0.01$. Un, untreated. little effect on tumor growth in both models, whereas the combined treatment led to complete tumor regression of all PROb tumor-bearing rats and significantly reduced CT26 tumor growth in mice (Figure 1, A and B).

Altogether, these experiments demonstrated synergistic antitumor effects between CTX and BCG in 2 rodent tumor models.

Tumor rejection involved cytotoxic DCs. To analyze the cellular mechanism responsible for tumor rejection after CTX-BCG treatment, we first studied immune cell infiltration of PROb tumors and CT2 6 tumors by immunohistochemistry 7 days after the second BCG injection and by cytometry analysis 2 and 7 days after the second BCG injection, respectively. In both models, we showed that the population of $\mathrm{MHC}$ class $\mathrm{II}^{+}\left(\mathrm{MHC}-\mathrm{II}^{+}\right) \mathrm{CD} 11 \mathrm{c}^{+}$cells was increasing the most in treated tumors compared with all the other cell populations investigated (NK cells, T cells, B cells, or macrophages) (Figure 2, A and B, Table 1, and data not shown). In contrast, tumors from untreated animals were only weakly infiltrated by these mononuclear cells.

Given that the combined treatment induced a massive tumor infiltration by $\mathrm{MHC}-\mathrm{II}^{+} \mathrm{CD} 11 \mathrm{c}^{+}$cells, we tested the cytolytic role of these cells in vitro in comparison to $\mathrm{CD}^{+} \mathrm{T}$ lymphocytes. Magnetically enriched $\mathrm{CD} 11 \mathrm{c}^{+}$or $\mathrm{CD}^{+} \mathrm{T}$ cells from both rat and mouse subcutaneous tumors were incubated with PROb and CT26 cells, respectively, at different effector/target ratios. Unexpectedly, only CD11 $\mathrm{c}^{+}$cells and not $\mathrm{CD}^{+} \mathrm{T}$ cells from animals treated with CTXBCG were able to kill tumor cells in vitro (Figure 3, A and B, and Supplemental Figure 1; supplemental material available online with this article; doi:10.1172/JCI35890DS1). Extensive phenotypic analysis of DC subtypes revealed that the combined treatment mostly induced a large infiltration of CD11b ${ }^{+}$DCs (3-fold increase over untreated control) negative for F4/80 (data not shown) and at a lower level of CD8 $\alpha$ DCs. Of note, no significant tumor infiltration by Gr-1+ $1^{+}, \mathrm{B} 220^{+}, \mathrm{CD} 11 \mathrm{c}^{\mathrm{int}}, \mathrm{NK}-\mathrm{p} 46^{-}$plasmacytoid DCs or $\mathrm{B} 220^{+}, \mathrm{CD} 11 \mathrm{c}^{+}, \mathrm{NK}-\mathrm{p} 46^{+}$IFN- $\gamma$-producing killer DCs (IKDCs) was induced by the combined treatment (Figure $3 \mathrm{C}$ ).

To further characterize the function of these TIDCs, CD $11 \mathrm{c}^{+}$ CD $11 b^{+} \mathrm{MHC}-\mathrm{II}^{+} \mathrm{TIDC}\left(\mathrm{CD} 11 \mathrm{~b}^{+} \mathrm{TIDC}\right)$ or CD $11 \mathrm{c}^{+} \mathrm{CD} 8 \alpha^{+} \mathrm{MHC}-\mathrm{II}^{+}$ TIDC (CD8 $\alpha^{+}$TIDC) cells were sorted and tested for their capacity to kill CT26 cells. Interestingly, only CD $11 b^{+}$TIDCs exhibited cytotoxicity against tumor cells (Figure 3D). Moreover, we showed that CD $11 b^{+}$TIDCs isolated from CTX-BCG-treated CT26 tumors could acquire a mature phenotype, as demonstrated by upregulation of CD80, CD86, CD40, and I-A/I-E molecules (Supplemental Figure 2A). When injected into the footpad of naive mice, these cells could trigger a specific IFN- $\gamma$ production by tumor draining lymph node cells after an in vitro stimulation (Supplemental Figure $2 \mathrm{~B}$ ) and vaccinate naive mice specifically against CT26 cells (Supplemental Figure 2C). In contrast, CD11b+ TIDCs obtained from either untreated groups or groups treated only with CTX or BCG alone were unable to do so. Similarly, TIDCs from CTX-BCG-treated rats could stimulate PROb specific lymphocytes in vitro (Supplemental Figure 2D) and vaccinate specifically naive rats against PROb cells (Supplemental Figure 2E).

Altogether, these data demonstrate that the CTX-BCG combina-

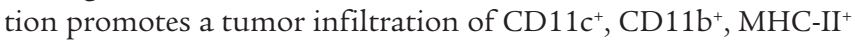
cells (CD11 $\mathrm{b}^{+}$TIDC) that kill tumor cells and exert APC functions.

$B C G$ induces TRAIL-dependent DC killing capacity through TLR2, TLR4, and TLR9 signaling. To determine which cytotoxic pathways were likely to be involved in the tumoricidal activity of CD11 $b^{+}$TIDCs, we tested the killing activity of CD11 $b^{+}$TIDCs 
A

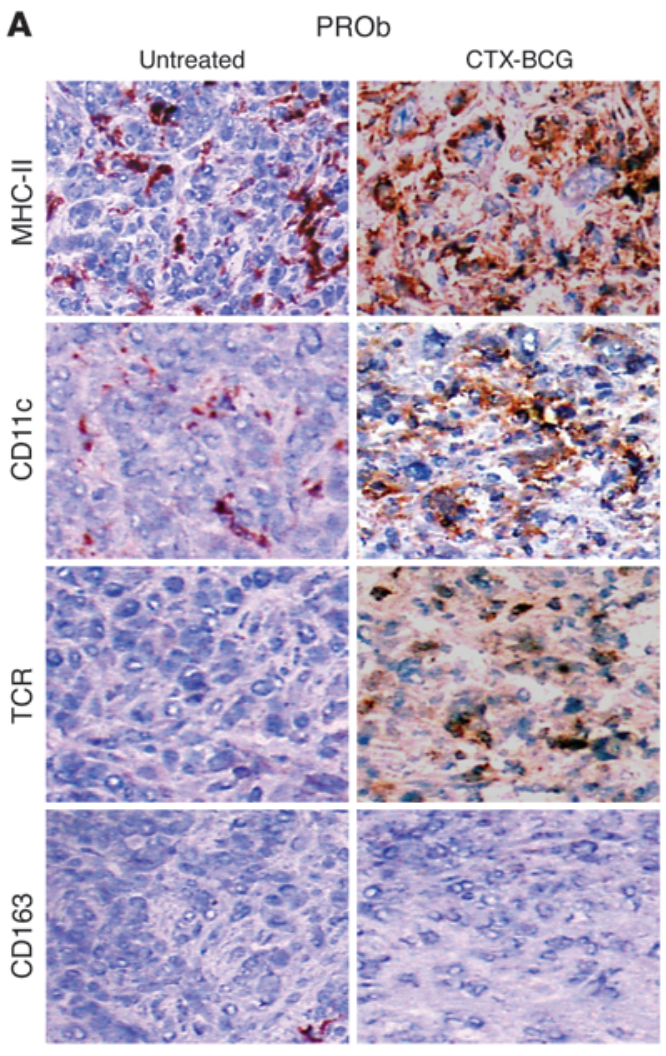

in the presence of $Z$-valine-alanine-aspartate-fluoromethyl ketone (Z-VAD-fmk), a pan-caspase inhibitor. As shown in Figure 4A, tumor cell death induced by CD $11 \mathrm{~b}^{+}$TIDCs from CTX-BCG-treated mice is prevented by Z-VAD-fmk. We additionally observed that tumor cell death induced by CD11 $\mathrm{b}^{+}$TIDCs is blunted by an antiTRAIL blocking $\mathrm{mAb}$ but not by an anti-Fas ligand blocking $\mathrm{mAb}$, $\mathrm{N}$-monomethyl-L-arginine (L-NMMA), which inhibits the inducible nitric oxide synthase, or concanamycin $\mathrm{A}$, which inhibits the perforin/granzyme pathway (Figure 4A). We ruled out a role for TNF- $\alpha$ to account for the cytotoxicity of TIDCs as we noted that CT26 and PROb cells were intrinsically resistant to TNF- $\alpha$-mediated cell death (data not shown). TRAIL expression was only detected at the surface of CD11 $\mathrm{b}^{+}$TIDCs sorted from treated mice and not on CD11 b+ TIDCs from control mice (Figure 4B). In contrast, TRAIL was not detected at the surface of intratumoral $T$ cells (data not shown). Furthermore, CD11b+ TIDCs sorted from untreated mice or DCs generated from the BM of mice (BM-DCs) incubated in vitro overnight with BCG induced TRAIL expression at their surface (Figure 4C) and triggered CT26 cell death in a TRAILdependent manner as demonstrated by the inhibitory effect of the blocking anti-TRAIL mAb (Figure 4D). BCG was recently reported to activate the immune system through TLR2, TLR4, and TLR9 $(25,26)$. We showed that TLR2, TLR4, and TLR9 ligands also enhanced BM-DC TRAIL expression while TLR3 ligand did not (Figure 4E). Using wild-type BM-DCs, wild-type BM-DCs treated with an oligodeoxynucleotide (IRS 954), which efficiently blocks TLR9 signaling, TRIF, Myd88, and TLR2- and TLR4-deficient BM-DCs, we observed by quantitative RT-PCR that the induction of Trail mRNA by BCG is dependent on TLR2, TLR4, and TLR9 molecules and on their shared adapter protein MyD88 but does not involve TRIF (and thus TLR3) signaling pathway (Supple-

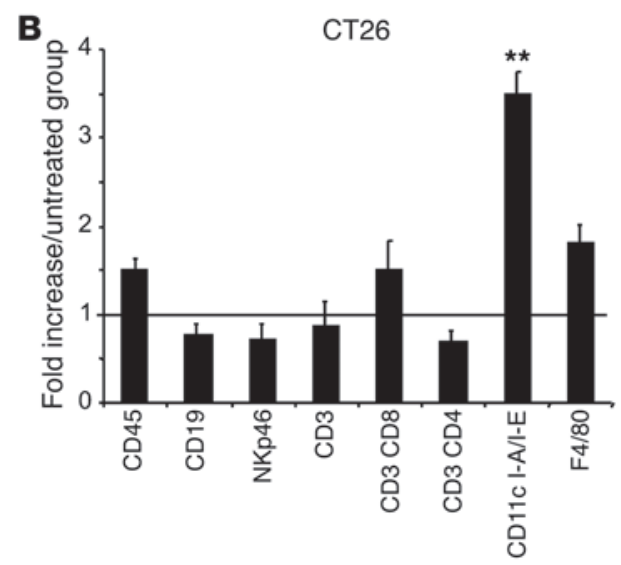

\section{Figure 2}

CTX-BCG treatment induces tumor infiltration by myeloid DCs. (A) MHC-II, CD11C, TCR, and CD163 immunohistochemical labeling of untreated PROb tumors or tumors obtained 7 days after the last BCG injection in animals treated by CTX-BCG. Original magnification, $\times 40$. (B) FACS analysis of the recruitment of leukocyte subpopulations (indicated in horizontal line) into CT26 tumors 2 days after the last BCG injection. Fold increase was calculated by dividing the absolute number of cells found in treated animals by the absolute number of cells found in untreated animals. Values represent mean \pm SEM. ${ }^{\star *} P<0.01$.

mental Figure 3). To investigate the role of TLR in the antitumor effects mediated by CTX and BCG in vivo, we compared the ability of the combined treatment to promote antitumor effects in wildtype, TLR2-, TLR4-, and MyD88-deficient BALB/c mice bearing

\section{Table 1}

Immunohistochemical analyses of tumor-infiltrating inflammatory cells

\begin{tabular}{lcccc}
\hline & \multicolumn{2}{c}{ Untreated } & \multicolumn{2}{c}{ CTX-BCG treated } \\
& $\begin{array}{l}\text { Tumor } \\
\text { periphery }\end{array}$ & $\begin{array}{c}\text { Tumor } \\
\text { center }\end{array}$ & Tumor & Tumor \\
periphery & center \\
Tumor cells & 0 & ++++ & 0 & + \\
(12C mAb) & & & & \\
CD11c & + & + & ++ & +++ \\
CD11b & + & ++ & +++ & +++ \\
CD68 & ++ & ++ & +++ & ++++ \\
MHC-II & ++ & ++ & +++ & ++++ \\
CD80 & 0 & 0 & + & ++ \\
CD86 & 0 & 0 & ++ & ++ \\
CD163 & ++ & 0 & + & 0 \\
TCR & ++ & 0 & ++ & +++ \\
CD4 & + & + & + & + \\
CD8 & + & + & ++ & +++ \\
CD161 & + & 0 & + & 0 \\
& & & &
\end{tabular}

Semiquantitative evaluation of antigen expression and location in tumor sections. Analysis was performed 7 days after the second BCG injection in either control or CTX-BCG-treated group. Two independent experiments were performed, each on 3 individual tumors. 0 , no labeled cells; ,$+ 10 \%-20 \%$ labeled cells; ++, 20\%-40\% labeled cells; +++, 40\%-60\% labeled cells; ++++, 60\%-80\% labeled cells. 
A
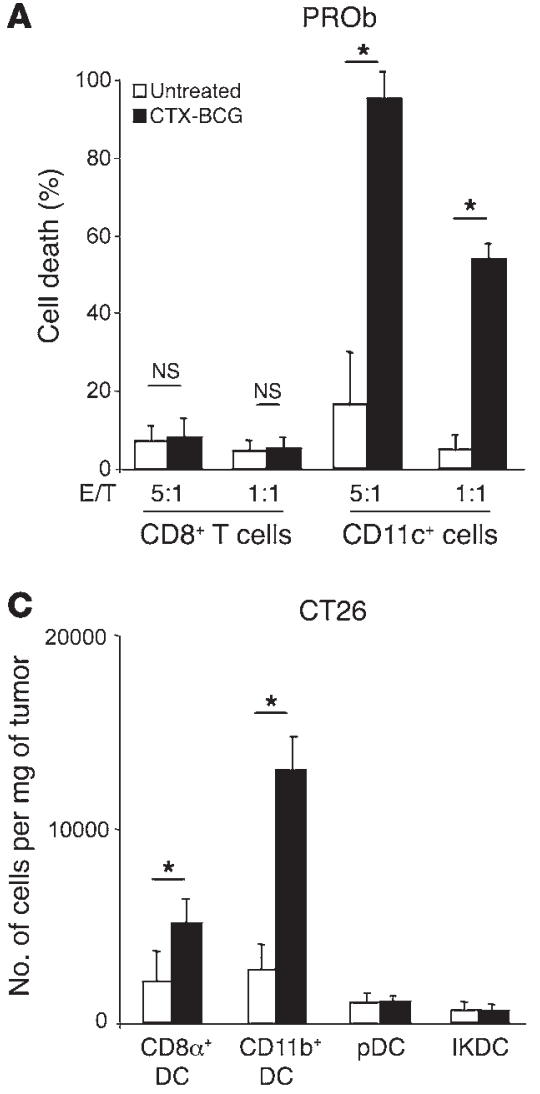

B

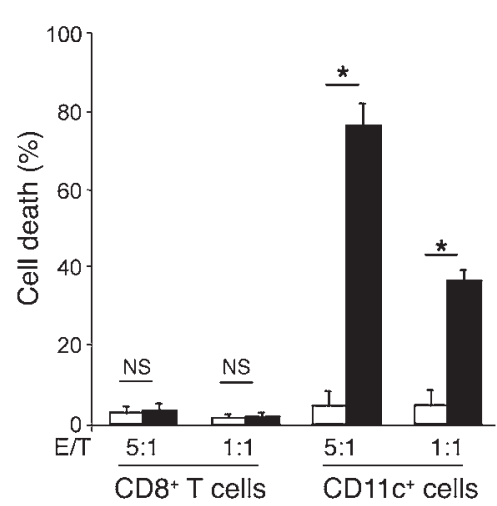

D

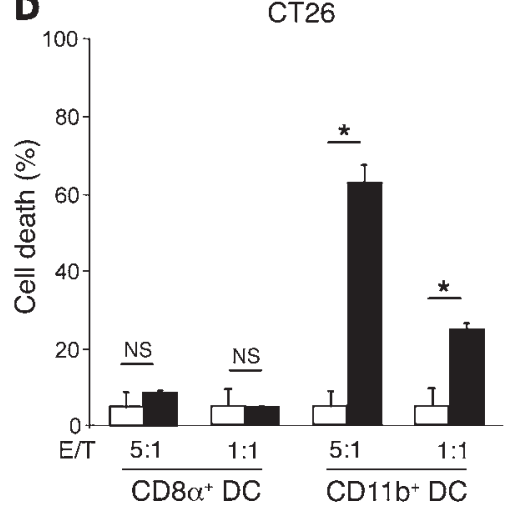

\section{Figure 3}

Myeloid DCs are cytotoxic against tumor cells. (A) For 48 hours, $5 \times 10^{4}$ or $1 \times 10^{4}$ TIDCs or CD8 ${ }^{+}$ $T$ cells isolated from tumors of untreated or CTXBCG-treated rats were incubated with $1 \times 10^{4}$ PROb cells. Cytotoxic effects on PROb cells were determined using a crystal violet assay. E/T, effector/target ratio. (B) For 48 hours, $5 \times 10^{4}$ or $1 \times 10^{4}$ TIDCs or CD8 ${ }^{+} \mathrm{T}$ cells isolated from CT26 tumors of untreated or CTX-BCG-treated mice were incubated with $1 \times 10^{4} \mathrm{CT} 26$ cells for 48 hours. Cytotoxic effect on CT26 cells was determined using a crystal violet assay. (C) FACS determination of the absolute number of DC subpopulations induced by the combined treatment in the CT26 model per mg of tumor. CD8 $\alpha^{+} \mathrm{DC}, \mathrm{CD} 8 \alpha^{+} \mathrm{CD} 11 \mathrm{C}^{+} \mathrm{MHC}-\mathrm{II}+\mathrm{CD} 45^{+}$; CD11b+ DC, CD11b+CD11c+MHC-II+CD45+; pDC, Gr1+B220+NK-p46-CD11 int $^{\text {int }} 45^{+}$; IKDC, Gr1B220+NK-p46+CD11 c ${ }^{+} \mathrm{CD} 45^{+}$. (D) For 48 hours, $5 \times 10^{4}$ or $1 \times 10^{4}$ CD8 $\alpha^{+}$TIDCs or CD11 b+ TIDCs isolated from untreated or CTX-BCG-treated mice were incubated with $1 \times 10^{4} \mathrm{CT} 26$ cells. Cytotoxic effect on the CT26 cells was determined using a crystal violet assay. For each experiment, values represent mean \pm SEM. ${ }^{*} P<0.05$.
CT26 tumors. While tumors grew at the same kinetic in wild-type and in TLR-deficient mice (Figure 4F), the antitumor effect of the combined treatment was significantly hampered in $\mathrm{Tlr} 2^{-/-}, \mathrm{Tlr} 4^{-/-}$, or $M y d 88^{-1-}$ mice (Figure 4F). Similar results were achieved when wild-type mice were injected with an oligodeoxynucleotide (IRS 954), which efficiently blocks TLR9 signaling (data not shown), underlining the participation of TLR9 in the effects of CTX-BCG combination (Figure 4F).

We could establish in human settings that human DCs derived from monocytes (Mo-DCs) also expressed TRAIL after an in vitro BCG stimulation (Figure 5A) and became cytotoxic toward HCT116 human colon carcinoma cells (Figure 5B) and toward a panel of melanoma cell lines (Figure 5C). Moreover, their cytotoxicity could be blunted by an anti-TRAIL antibody or by Z-VAD-fmk, whereas L-NMMA and concanamycin A (Figure 5D) and anti-Fas ligand and anti-TNF- $\alpha$ antibodies were ineffective (data not shown).

Overall, these data demonstrate that BCG induces TRAIL expression at the surface of DCs, either CD $11 b^{+}$TIDCs or BM-DCs, through TLR2, TLR4, or TLR9 signaling and promotes tumor cell killing in a TRAIL-dependent manner.

Tregs prevent BCG-induced TRAIL expression on CD11b+ TIDCs. We $(18,27)$ and others $(28)$ demonstrated that CTX administration decreased the number and inhibited the function of Tregs in the lymphoid organs. We here extend these findings by demonstrating that CTX decreased the percentage of Tregs that infiltrated CT26 and PROb tumors (Figure 6A and data not shown). DAPI staining indicated that, 2 days after CTX treatment, a large part of tumor-infiltrating Tregs were dying cells (Figure 6A). Further- more, mafosfamide, a metabolite of CTX, preferentially induces apoptosis of $\mathrm{CD} 4{ }^{+} \mathrm{CD} 25^{+}$Tregs in vitro compared with conventional $\mathrm{CD}^{+} \mathrm{CD} 25^{-} \mathrm{T}$ cells (Tconvs) (Supplemental Figure 4A). This cytotoxicity likely involved Foxp3 expression, as Foxp3 expression in Jurkat leukemic $\mathrm{T}$ cells sensitized these cells to mafosfamide (Supplemental Figure 4B). Finally, we demonstrated in CT26 tumor-bearing mice that the adoptive transfer of Tregs (but not Tconvs) performed concomitantly with the first administration of BCG dramatically reduced the antitumor effects of the combined treatment (Figure 6B). Therefore, we investigated whether Tregs could hamper TRAIL-dependent cytotoxicity of CD11b $\mathrm{b}^{+}$TIDCs described above. In vitro, Tregs but not Tconvs could prevent the upregulation of TRAIL molecules after BCG stimulation at the surface of CD11 $\mathrm{b}^{+}$TIDCs isolated from untreated CT26 tumorbearing mice (Figure 6C). A similar result was obtained using mouse BM-DCs (Figure 6D). Furthermore, when mouse BM-DCs were treated with BCG and cultured with Tregs in the presence of a transwell insert that separated DCs from Tregs, we demonstrated by quantitative RT-PCR that Tregs could no longer prevent TRAIL acquisition on BCG-treated DCs. This suggests that the inhibitory effect of Tregs on DCs is dependent on cell-to-cell contact (Figure $6 \mathrm{E})$. Accordingly, addition of Tregs, but not Tconvs, to the coculture of BCG-stimulated CD11 b $^{+}$TIDCs or BM-DCs inhibited their capacity to kill tumor cells (Figure 6, F and G). Cytotoxicity of human Mo-DCs against M45 melanoma cells was also inhibited when Mo-DCs were incubated with Tregs during BCG stimulation but not when Mo-DCs were incubated with Tconvs (Figure $6 \mathrm{H}$ ).

Altogether, these results demonstrate that in vitro, Tregs control the capacity of BCG to induce TRAIL expression at the surface of 


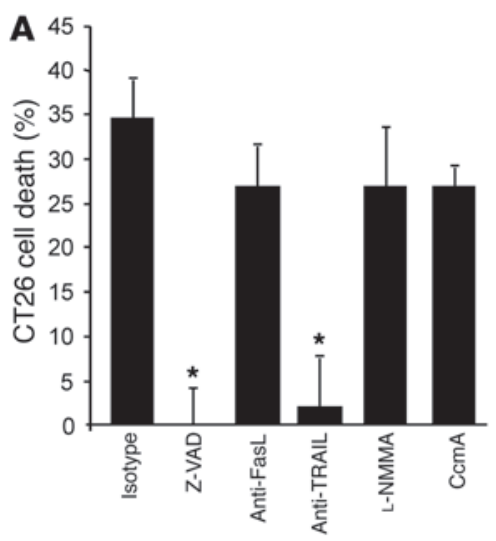

B
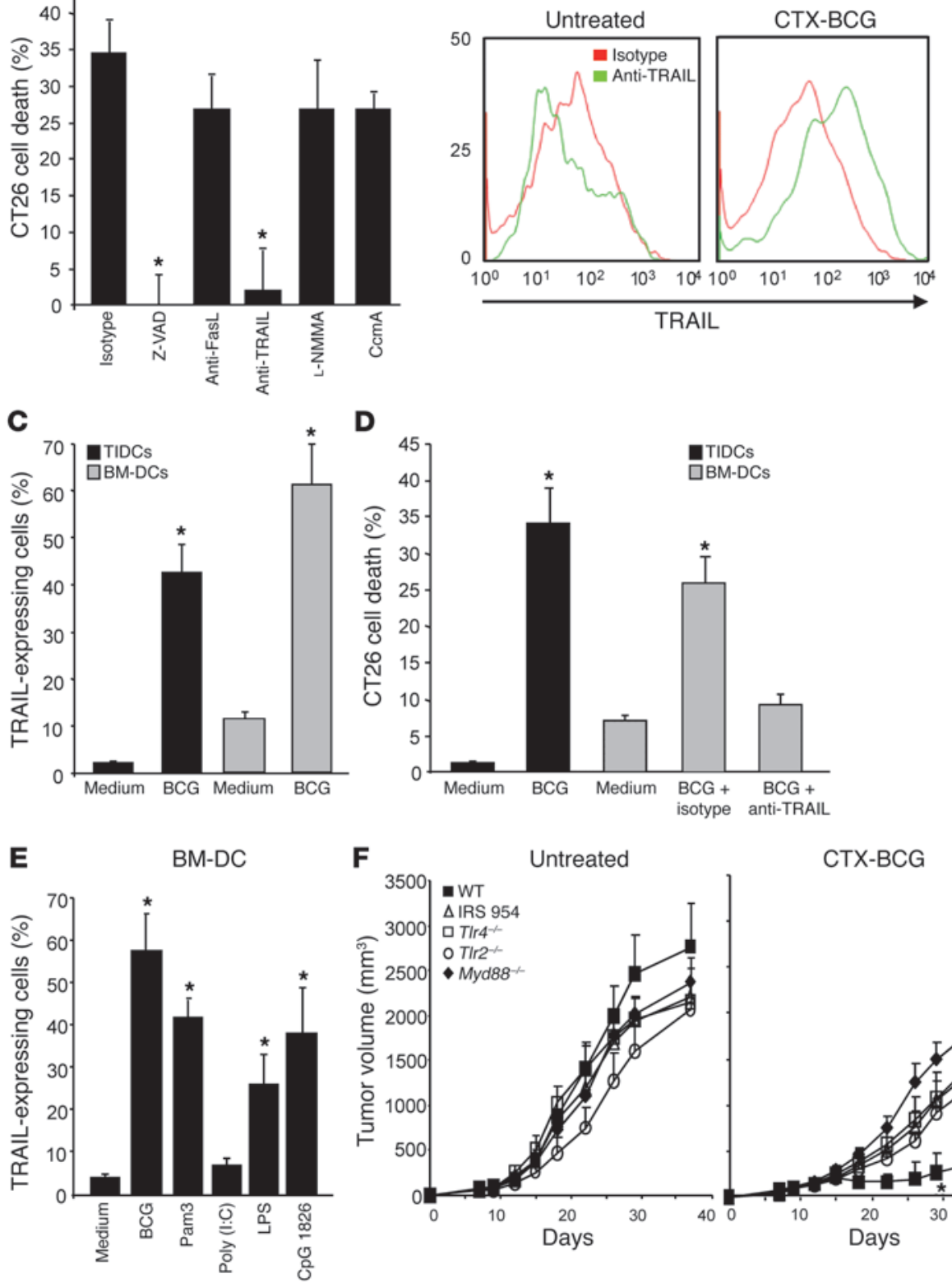

Figure 4

BCG endows DCs with killing capacities via TRAIL upregulation. (A) For 48 hours, $5 \times 10^{4} \mathrm{CD} 11 \mathrm{~b}+$ TIDCs isolated from CTX-BCG-treated mice were incubated with $1 \times 10^{4}$ CT26 cells. In some wells, Z-VAD-fmk (Z-VAD), blocking anti-Fas ligand (FasL), antiTRAIL mAbs, L-NMMA, or concanamycin $A(C \mathrm{cmA})$ were added. CD11 $\mathrm{b}^{+}$ TIDC cytotoxicity against CT26 cells was determined using a crystal violet assay. (B) FACS analysis of TRAIL expression on CD11 b+ TIDCs (CD45+) that infiltrated untreated CT26 tumor and tumor treated with CTX-BCG. (C) CD11 $b+$ TIDCs isolated from untreated CT26 tumors or BM-DCs were either untreated or cultured overnight with BCG $\left(8 \times 10^{5} \mathrm{CFU} / \mathrm{ml}\right)$. TRAIL expression was determined by FACS analysis on $\mathrm{CD} 11 \mathrm{C}^{+} \mathrm{I}-\mathrm{A} / \mathrm{I}-\mathrm{E}^{+}$gated cells and (D) $5 \times 10^{4}$ CD11 b $b^{+}$TIDCs or BM-DCs were incubated with $1 \times 10^{4}$ CT26 cells for 48 hours. A blocking anti-TRAIL mAb was also added to some of the wells containing BM-DCs activated by BCG. Cytotoxic effect on the CT26 cells was determined using a crystal violet assay. (E) BMDCs were incubated overnight in the absence or presence of ligands for TLR2 (Pamv3CSK4 [Pam3]), TLR3 [Poly(I:C)], TLR4 (LPS), TLR9 (CpG ODN 1826 [CpG 1826]), or with BCG $\left(8 \times 10^{5} \mathrm{CFU} / \mathrm{ml}\right)$. TRAIL expression was determined by FACS analysis on $\mathrm{CD} 11 \mathrm{C}^{+} \mathrm{I}-\mathrm{A} / \mathrm{I}-\mathrm{E}^{+}$gated cells. (F)

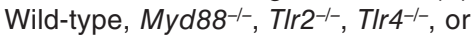
wild-type mice treated with i.p. injections of TLR9 inhibitor ODN (IRS 954) every 3 days received a subcutaneous injection of $5 \times 10^{5}$ CT26 tumor cells. In the same experiment, 2 groups of mice received either saline or the combined treatment. Data represent mean \pm SEM. ${ }^{*} P<0.05$.
CD11 $\mathrm{b}^{+}$TIDCs or conventional DCs and the subsequent tumoricidal activity of TRAIL expression.

Tregs compromise the success of CTX-BCG treatment via inbibition of TRAIL-dependent TIDC cytotoxicity. We next sought to analyze the direct cytotoxicity of TIDCs in vivo. Nude mice inoculated subcutaneously with CT26 cells were treated with intratumoral injections of BM-DCs stimulated or not with BCG. Importantly, the antitumor effects of BM-DCs were correlated to their level of TRAIL expression described in Figure 4C, as only TRAIL expressing BCG-stimulated BM-DCs significantly delayed tumor growth, while unstimulated BM-DCs had no impact on tumor growth (Figure 7A). Moreover, FACS analysis revealed that adoptive transfer of Tregs (but not Tconvs) inhibited the capacity of the combined treatment to induce TRAIL expression on CD $11 b^{+}$TIDCs (Figure $7 \mathrm{~B}$ ). Finally, in vivo inhibition of TIDC-mediated cytotoxicity using systemic injection of TRAIL blocking $\mathrm{mAb}$ or intratumoral injection of Z-VAD-fmk could blunt the antitumor effects of the combined treatment in immunocompetent mice (Figure 7C).

Altogether, these data demonstrate that TRAIL expressing TIDCs directly control tumor growth in vivo and that Tregs control TRAIL expression on their surface and therefore the antitumor efficacy of the CTX-BCG treatment.

\section{Discussion}

The present study demonstrates that mouse CD $11 b^{+}$TIDCs and conventional mouse and human DCs could be rendered cytotoxic against tumor cells through induction of TRAIL expression. This cytotoxic property is induced by BCG, which activates TIDCs through TLR, and is tightly controlled by Tregs.

BCG is a consensual treatment of superficial bladder cancer (29), and its use as an adjuvant treatment reduces the rate of recurrence after colon cancer surgery (30). BCG modifies the immune 
A
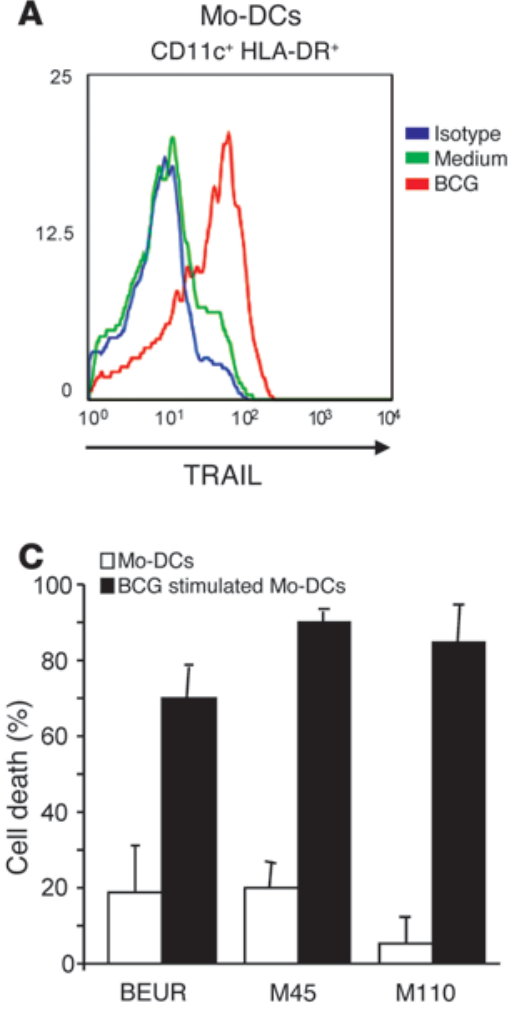

B
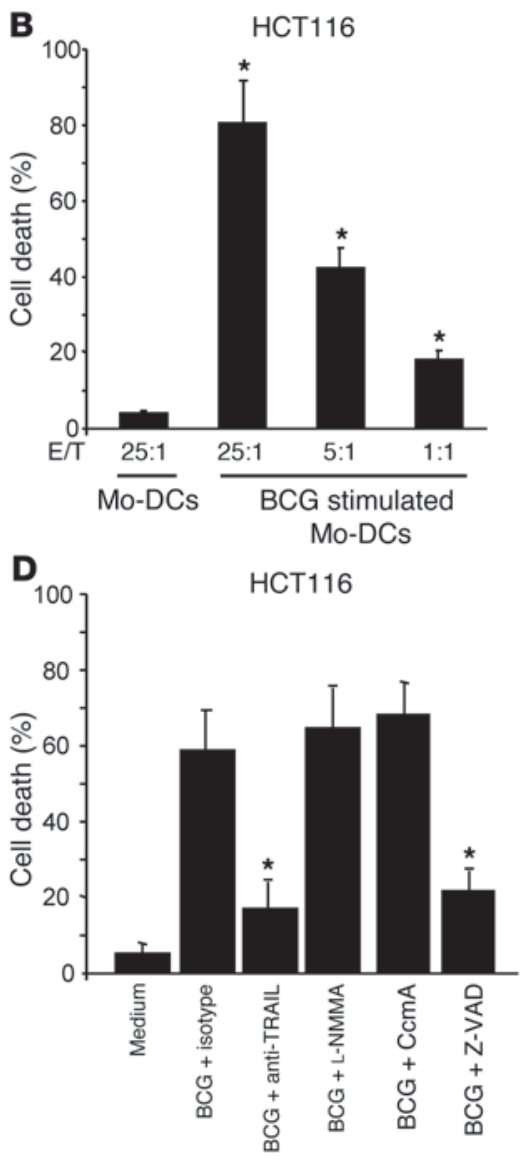

\section{Figure 5}

BCG activated human Mo-DCs are cytotoxic against human cell lines in a TRAIL-dependent manner. (A) FACS analysis of TRAIL expression on $\mathrm{CD}_{11 \mathrm{C}^{+}} \mathrm{HLA}^{-D R^{+}} \mathrm{DCs}$ derived from human CD14+ peripheral blood monocytes after overnight incubation with BCG $\left(8 \times 10^{5} \mathrm{CFU} / \mathrm{ml}\right)$ or PBS. (B) Mo-DCs were either untreated or cultured overnight with BCG and then incubated with $1 \times 10^{4}$ HCT116 cells for 48 hours at various effector/target ratios. Cytotoxic effect on HCT116 cells was determined using a crystal violet assay. (C) Mo-DCs were incubated overnight in the absence or presence of $8 \times 10^{5} \mathrm{CFU} / \mathrm{ml}$ of BCG. Then $5 \times 10^{4} \mathrm{Mo}-\mathrm{DCs}$ were incubated with $1 \times 10^{4}$ tumor cells (M45, M96, and BEUR melanomas) for 48 hours and tumor cell cytotoxicity was determined using a crystal violet assay. (D) BCG stimulated Mo-DC cytotoxicity against HCT116 cells was determined by a crystal violet assay in the presence of anti-TRAIL, L-NMMA, concanamycin A, and Z-VAD-fmk at a 5:1 effector/target cell ratio. Values from 1 experiment out of 2 represent mean \pm SEM. ${ }^{*} P<0.05$. response through its effect on TLR2, TLR4 (25), and TLR9 (26) and induces IFN- $\gamma$ production in human DCs via TLR2 (31). Some reports demonstrated that BCG could induce TRAIL expression on human neutrophil cell surface (32), and high TRAIL protein levels in the urine of bladder cancer patients treated with BCG were associated with a favorable response to treatment (33). TRAIL expression on human plasmacytoid DCs or Mo-DCs was described after TLR7 triggering or IFN- $\alpha$ stimulation, respectively $(34,35)$. In mice, BCG or TLR 2 or TLR4 ligands were shown to induce TRAIL expression at the surface of peritoneal macrophages (36). Here we show for what we believe to be the first time that BCG induces TRAIL expression at the surface of mouse CD $11 b^{+}$TIDCs and conventional DCs. We also demonstrate that human Mo-DCs also express TRAIL upon BCG stimulation and then kill colon carcinoma and melanoma cell lines in a TRAIL-dependent manner.

We $(18,37)$ and others $(28,38)$ have demonstrated that low doses of CTX could selectively deplete Tregs in the blood and lymphoid organs of tumor-bearing animals. Here we show that CTX also decreases the number of Tregs that infiltrate the tumor. Treg sensitivity to CTX-induced cell death appears to be specific, both in vitro and in vivo. Tregs express Foxp3, a transcription factor involved in their immunosuppressive effect (39) that is associated with an increased expression of proapoptotic molecules (40), which could contribute to their higher sensitivity to low dose of CTX. Accordingly, stable transfection of Foxp3 into a leukemic $\mathrm{T}$ cell line enhances its sensitivity to mafosfamide in vitro. Although CTX could also directly kill tumor cells or induce IFN type I production that would impact on tumor growth (41), its main effect in our settings appeared to be Treg depletion since an adoptive transfer of Tregs abrogates the antitumor effects of the CTX and BCG treatment.

We previously demonstrated that Tregs controlled NK cell cytotoxicity in mouse and human tumor settings $(20,42)$. Tregs were also involved in the control of the cytotoxic functions of classical CTL (19) but, to the best of our knowledge, no studies on the ability of Tregs to alter the killing potential of DCs were previously carried out. Here, by performing CTX-induced Treg depletion and an adoptive transfer of Tregs, we delineate another mechanism used by Tregs to mediate immunosuppression. While up to now Tregs were only known to affect DC maturation, to our knowledge we are the first to demonstrate that Tregs can control the cytotoxic effect of TIDCs and conventional DCs. The mechanism by which Tregs inhibit DC cytotoxicity remains to be discovered. Many potential mechanisms by which Tregs mediate their function have been described (43). However, it is noteworthy that among all the described Treg inhibitory mediators only TGF- $\beta$ was reported to possess an inhibitory effect on TRAIL expression. Indeed, the cytotoxicity of other killer cells such as NK cells and IKDCs is mainly dependent on TRAIL and could be blunted by TGF- $\beta(44,45)$. We can therefore hypothesize that Treg membrane-bound TGF- $\beta$ could blunt DC cytotoxicity as previously reported for NK cells $(20,46)$.

The ability of DCs to foster antitumoral immunity by triggering tumor cell death is an emerging concept $(47,48)$. Rat splenic and BM-derived DCs can trigger tumor cell lysis in vitro through NKR-P1 and nitric oxide production, respectively 


\section{A} CD3 ${ }^{+} \mathrm{CD} 127^{-}$gated
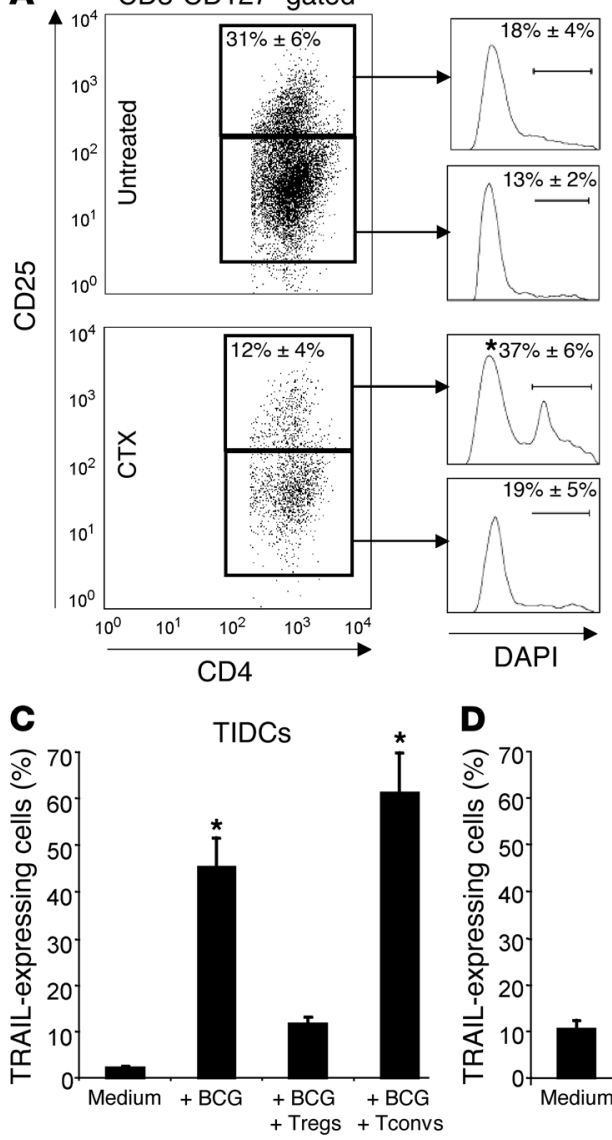

D

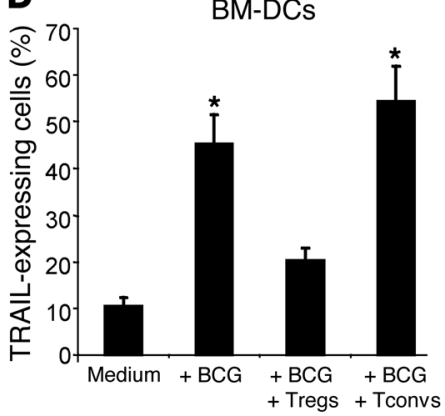

E
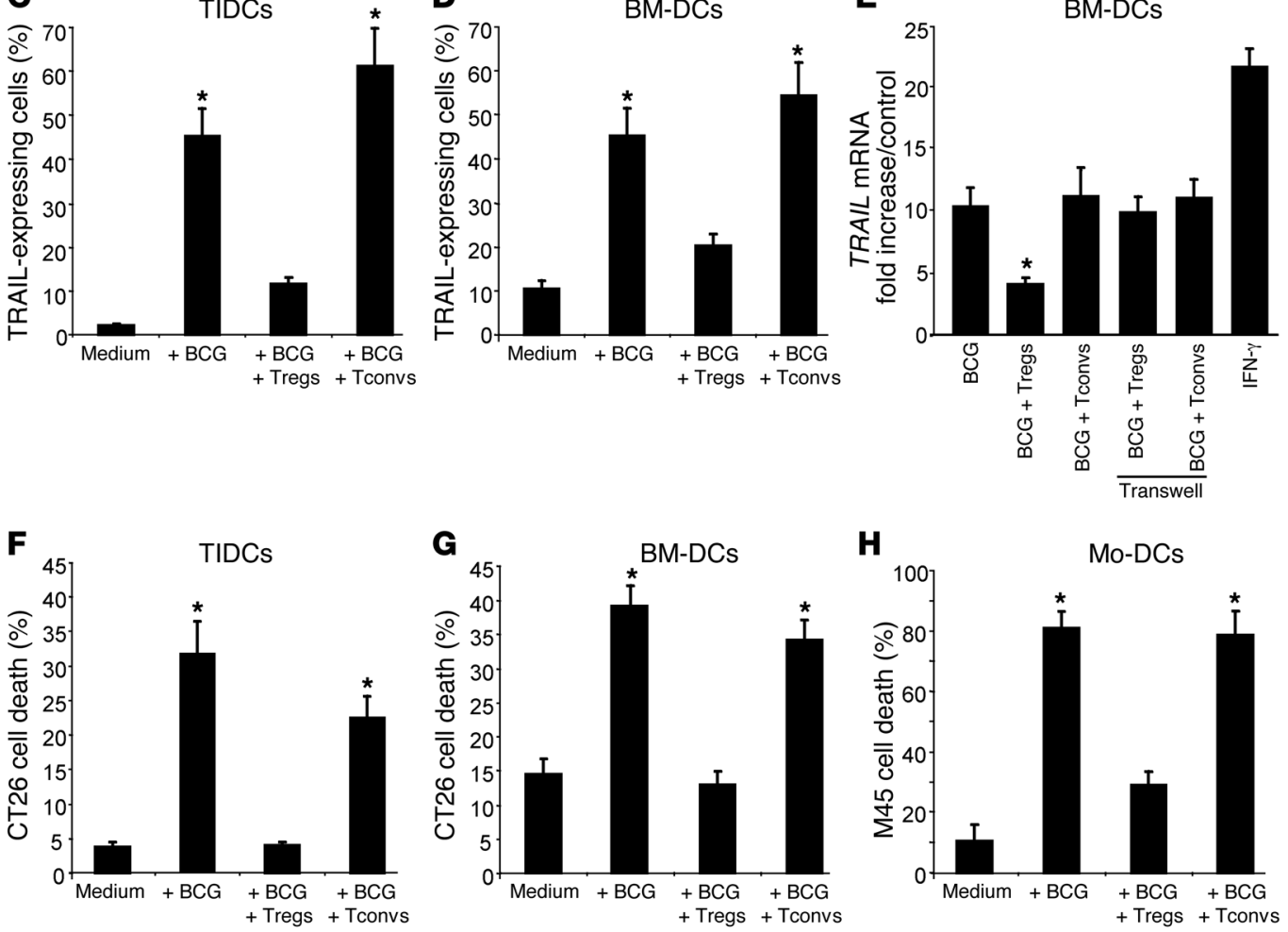

$\mathbf{H}$

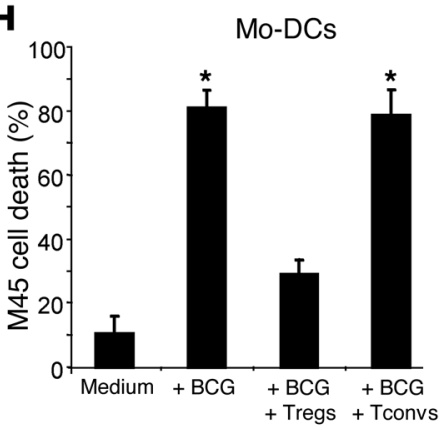

Figure 6

Tregs are selectively killed by CTX and prevent TRAIL-dependent cytotoxicity of TIDCs. (A) FACS analysis of CD4 $4^{+}$CD25 $($Treg) cells in the $\mathrm{CD}^{+}{ }^{+} \mathrm{CD} 4{ }^{+} \mathrm{CD} 127^{-}$tumor-infiltrating T cell subsets. The percentage of Tregs and dead cells in tumors were determined by DAPI labeling 2 days after CTX injection. Numbers indicate the percentage of cells \pm SD. (B) The day of the first BCG injection, 2 groups of mice were adoptively transferred with $1 \times 10^{6}$ Tregs or $1 \times 10^{6} \mathrm{CD}^{+} \mathrm{CD} 25^{-}$(Tconv) cells ( $n=5$ in each group). (C) CD11b+ TIDCs from untreated CT26 tumor-bearing mice were incubated overnight with BCG and with Tregs or Tconvs at a ratio 1:1. TRAIL expression was determined by FACS analysis. (D) Same experiment as in $\mathbf{C}$ but using mouse BM-DCs instead of CD11 b+ TIDCs. (E) Same experiment as in D but in some wells DCs were separated from T cells by a 0.4- $\mu \mathrm{m}$ Transwell insert. TRAIL and GAPDH mRNA levels were determined by quantitative RT-PCR on CD11c cells sorted by magnetic isolation. BM-DCs incubated with IFN- $\gamma$ represent a positive control of TRAIL mRNA expression. Each value is expressed as fold increase from medium control after normalization with GAPDH. (F) CD11b+ TIDCs from untreated CT26 tumorbearing animals were incubated overnight with BCG and with Tregs or Tconvs at a ratio $1: 1$. Then these cells $\left(5 \times 10^{4}\right.$ cells) were cultured with $1 \times 10^{4}$ CT26 cells for 48 hours. TIDC cytotoxicity on CT26 cells was determined using crystal violet staining. (G) Same experiment as in $\mathbf{F}$ but using mouse BM-DCs instead of CD11 b+ TIDCs. (H) Same experiment as in F but using mouse Mo-DCs instead of CD11b+ TIDCs and M45 melanoma cells instead of CT26 cells. Values from 1 experiment out of 2 represent mean \pm SEM. ${ }^{\star} P<0.05$. 

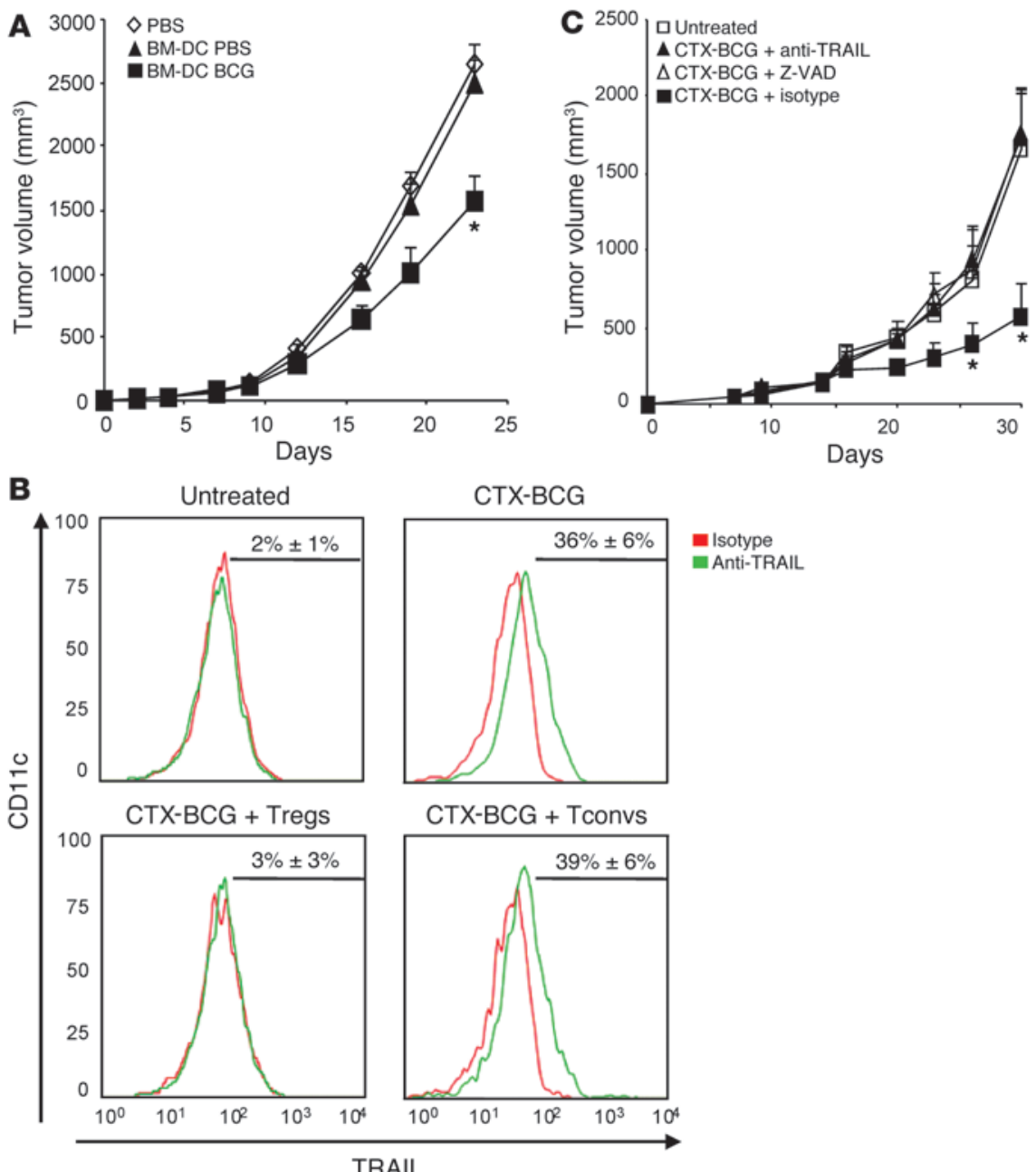

TRAIL

\section{Figure 7}

Treg control TRAIL-mediated antitumor effect of CTX-BCG treatment in vivo. (A) Unstimulated or overnight BCG stimulated BM-DCs $\left(1-2 \times 10^{6}\right.$ cells) were injected intratumorally in nude mice $2,4,6$, and 10 days after subcutaneous CT26 cell injection ( $n=5$ in each group). (B) FACS analysis of TRAIL expression in CD11 $\mathrm{b}^{+}$TIDCs $\left(\mathrm{CD} 45^{+}\right)$from CT26 untreated or treated tumors. The day of the first BCG injection, $1 \times 10^{6}$ Tregs, $1 \times 10^{6}$ Tconvs, or $100 \mu$ I PBS were injected intravenously, and mice were killed 2 days after the second BCG intratumoral injection. Numbers indicate the percentage of cells $\pm S D$. (C) Four groups of $5 \mathrm{BALB} / \mathrm{c}$ mice received a subcutaneous injection of $5 \times 10^{5}$ CT26 tumor cells. Seven days later, mice received the combined treatment alone or in combination with intratumoral or i.p. injection of Z-VAD-fmk or anti-TRAIL mAb respectively. Untreated mice represent control group. For each experiment, animals were monitored twice a week for tumor volume. Values in $\mathbf{A}$ and $\mathbf{C}$ represent mean \pm SEM. ${ }^{\star} P<0.05$.
$(49,50)$. Human cord blood $\mathrm{CD} 4^{+}(51)$ and peripheral blood CD14+-derived DCs (52) could also exert cytotoxic effects in vitro. Tumor-infiltrating cells with NK functions and DC markers called IKDCs were demonstrated to kill tumor cells through TRAIL and control tumor growth, although in contrast to conventional DCs and TIDCs described in our study, their ability to act as professional APCs and to induce a strong Th 1 polarization remains to be established $(23,24,53-55)$. Here cytotoxic TIDCs are capable of antigen presentation as they were able to upregulate MHC-II and costimulatory molecules upon the combined treatment and to prime naive $\mathrm{T}$ cells.

In conclusion, this report emphasizes the remarkable efficacy of a combination of CTX and BCG in treating colon carcinomas in 2 rodent models. These findings illustrate 2 steps that are required for achieving eradication of established tumors by immunotherapy. The first step is to relieve the immune system from the tumordependent immune tolerance mediated by Treg, which prevents the development of an efficient antitumor immune response. The second step is the activation of the immune response. Implementing this strategy in the clinic may represent a new challenge for the next years. By acting directly on CD $11 b^{+}$TIDCs through their TLRs, BCG intratumoral injections may achieve their activation, making these cells cytotoxic against tumor cells and able to acquire antigen-presenting function. We propose that Treg depletion fol- lowed by activation of TIDCs to transform them into tumor cell killers and efficient APCs might be a new and powerful way to build vaccine against established tumors.

\section{Methods}

Animals. Inbred BD-IX strain rats, used at 10-12 weeks of age, were bred at Centre de Zootechnologie. BALB/c (H-2 $\left.{ }^{\mathrm{d}}\right)$ mice were purchased from Janvier and male nude swiss mice were obtained from the animal facility of the Gustave Roussy Institute and used at 8-12 weeks of age. Tlr4 $4^{--}, \mathrm{Tlr} 2^{-/}$, Trif ${ }^{-/}$, and $M y d 88^{-/-}$mice (backcrossed 10 times on a BALB/c background) were provided by Grégoire Lauvau. Animal use and handling were approved by the Comité régionale d'éthique animale, Dijon, France, and experiments were performed following European laws for animal experimentation.

Cell lines. PROb cells were established from a 1,2-dimethylhydrazineinduced colon carcinoma in BD-IX rats (56). PROb cells transfected with a cDNA encoding H2B-GFP (BD) were obtained after selection with blasticidine $(20 \mu \mathrm{g} / \mathrm{ml}$; Invitrogen). Mouse CT26 colon and TS/A mammary adenocarcinoma cancer cell lines and rat PROb and G1V1A1 glioma cell lines were cultured at $37^{\circ} \mathrm{C}$ under $5 \% \mathrm{CO}_{2}$ in RPMI 1640 complete medium. Jurkat cells were obtained from ATCC (catalog no. TIB-152; ATCC) and stably transfected with Foxp3 full-length cDNA plasmid, which was kindly provided by Steven Ziegler (Benaroya Research Institute, Seattle, Washington, USA). Human HCT116 colon carcinoma, Jurkat leukemia cells, and melanomas (Beur, M45, and M110; kindly 
provided by F. Jotereau, Institut de Biologie/CHR, Nantes, France) were cultured in DMEM complete medium.

Tumor models and immunotherapy. PROb tumors and CT26 tumors were obtained by subcutaneously injecting $1 \times 10^{6}$ cells in the thoracic wall of BD-IX rats and $5 \times 10^{5}$ cells in the flank of BALB/c mice. One i.p. injection of CTX (Sigma-Aldrich) was performed at $30 \mathrm{mg} / \mathrm{kg}$ body weight on day 28 for rats and $100 \mathrm{mg} / \mathrm{kg}$ body weight on day 7 for mice after tumor cell injection. Then rats received, 7 and 14 days later, 2 intratumoral injections of $8 \times 10^{5} \mathrm{CFU}$ of BCG (Pasteur-Merieux) while mice received, 2 and 7 days later, 2 intratumoral injections of $8 \times 10^{4} \mathrm{CFU}$ of BCG in $100 \mu \mathrm{l}$ of isotonic $\mathrm{NaCl}$ solution. Control groups of tumor-bearing rats and mice received CTX alone, BCG alone, or saline injections. In vivo blockade of TRAIL was performed by injecting mice i.p. 3 times a week with $250 \mu \mathrm{g}$ of a neutralizing TRAIL-specific antibody (clone N2B2) obtained from H. Yagita (Juntendo University School of Medicine) (57). Intratumoral injections of Z-VAD-fmk (10 $\mu \mathrm{l}$ of a $100 \mathrm{mM}$ solution), a pan-caspase inhibitor, were performed twice. TLR9 from wild-type mice was blocked by 3 weekly i.p. injections of $50 \mu \mathrm{g}$ of IRS 954, an immunoregulatory DNA sequence inhibitor kindly provided by F.J. Barrat from Dynavax Technology, Berkeley, California, USA (58).

Lymphocyte and TIDC isolation. Tregs $\left(\mathrm{CD} 4^{+} \mathrm{CD} 25^{+}\right)$or Tconvs $\left(\mathrm{CD} 4^{+} \mathrm{CD} 25^{-}\right)$ were isolated from the spleen of CT2 6 tumor-bearing mice using a magnetic bead selection (Miltenyi Biotec) according to the manufacturer's protocol. About $90 \%$ of the positively selected Tregs were $\mathrm{CD} 4^{+} \mathrm{CD} 25^{+}$based on FACS analysis. Tregs were incubated overnight with $5 \mu \mathrm{g} / \mathrm{ml}$ of anti-CD3 and anti-CD2 $8 \mathrm{mAbs}, 100 \mathrm{U} / \mathrm{ml}$ of IL2, and $1 \mathrm{ng} / \mathrm{ml}$ of TGF- $\beta$. Tconvs were cultured in a similar way without TGF- $\beta$. For tumor-infiltrating cell isolation, tumors were mechanically dissociated, then incubated 2 times with $0.5 \mathrm{mg} / \mathrm{ml}$ collagenase (Sigma-Aldrich) for 30 minutes at $37^{\circ} \mathrm{C}$ on a rocking platform. Populations of TIDCs and $\mathrm{CD}^{+} \mathrm{T}$ cells were either enriched using anti-CD11c or anti-CD8 $\alpha$ microbeads according to the manufacturer's protocol (Miltenyi Biotec) or sorted on a MoFlo instrument (Dako) after staining for CD45, CD11c, CD11b, and MHC-II. The purity of cell preparation exceeded $90 \%$ when cells were sorted and $70 \%$ when they were magnetically selected, based on flow cytometry analysis.

Immunofluorescence staining and flow cytometry. We purchased all mouse antibodies (Percp anti-CD8 $\alpha$, APC anti-CD11c, FITC anti-I-A/I-E, FITC anti-CD11b, FITC anti-Gr1, APC-Cy7 anti-B220, FITC anti-CD19, PE anti-F4/80, PE anti-CD80, PE anti-CD86, PE anti-CD40, APC anti-CD3, PE-Cy7 anti-CD4, PE anti-CD25, FITC anti-CD127) from BD Biosciences - Pharmingen, except PE anti-TRAIL and PE-Cy5.5 anti-CD45 antibodies, which were purchased from eBioscience. Anti-NKp46 antibody was kindly provided by E. Vivier (CIML, Marseille, France). Human PE anti-TRAIL and PE-Cy7 anti-CD11c were from eBioscience and BD Biosciences - Pharmingen, respectively. We incubated cells with antibodies for 30 minutes at $4^{\circ} \mathrm{C}$ and after a wash step we analyzed them with an LSRII (BD) and a FACS Diva software (BD). DAPI (Sigma-Aldrich) was added immediately before acquisition to exclude dead cells in tumors. We analyzed data with FlowJo 7.2 software (Tree Star Inc.).

Tumor immunohistochemical analysis. PROb tumors from treated rats were surgically removed, embedded in Tissue-Tek (Miles Inc.), and snap-frozen in methylbutane cooled in liquid nitrogen. Frozen sections $(10 \mu \mathrm{m})$ were thawed, fixed in acetone at $4^{\circ} \mathrm{C}$, and incubated with various specific mAbs obtained from Serotec or BD Biosciences - Pharmingen as previously described (59).

$B M$ - and Mo-DC generation and TLR ligand stimulation. Murine BM-DCs were propagated as already described (37) in Iscove's medium (Sigma-Aldrich) containing $5 \%$ of supernatant from $J 558$ cell culture and used when the proportion of DCs within the culture was above $75 \%$ as determined by CD $11 \mathrm{c}$ and MHC-II labeling. TLR ligands, such as Pam3CSK4 $(10 \mu \mathrm{g} / \mathrm{ml}$; Invivo- gen), LPS (1 $\mu \mathrm{g} / \mathrm{ml}$; Sigma-Aldrich), poly(I:C) (5 $\mu \mathrm{g} / \mathrm{ml}$; Sigma-Aldrich), CPG 1668 (5 $\mu \mathrm{g} / \mathrm{ml}$; MWG Biotech), were incubated overnight with BMDCs or TIDCs. Human monocytes (CD14+), Tregs (CD4+CD25+CD127-), and Tconvs $\left(\mathrm{CD}^{+} \mathrm{CD} 127^{+}\right)$were isolated by sorting PBMCs of healthy volunteers on a MoFlo instrument (Dako) after staining with the following mAbs: FITC anti-CD127 (eBioscience), PE anti-CD25 (Miltenyi Biotec), PE-Cy7 anti-CD4 (BD Biosciences - Pharmingen), and APC anti-CD14 (BD Biosciences - Pharmingen). All donors gave written informed consent. The purity of each cell population was about $90 \%$. CD $14^{+}$cells were cultured for 4 days with GM-CSF (1,000 U/ml; R\&D Systems) and IFN$\alpha 2 \mathrm{~b}(1,000 \mathrm{U} / \mathrm{ml}$; Introna Schering Plough), and Tregs and Tconvs were maintained in vitro with $1 \mathrm{CD} 3 / \mathrm{CD} 28$ bead (Dynal Biotech ASA) per T cell, $100 \mathrm{UI}$ of IL-2, and $5 \mathrm{ng} / \mathrm{ml}$ of TGF- $\beta$ for Treg culture.

TRAIL expression by quantitative RT-PCR. RNA isolation from BM-DCs was performed with the RNeasy Mini Kit (Qiagen) following the manufacturer's recommendations. Total RNA $(500 \mu \mathrm{g})$ was reverse-transcribed in a $20 \mu \mathrm{l}$ volume reaction. The cDNAs were then diluted 1:20 in nuclease-free water. cDNAs equivalent to $6.25 \mathrm{ng}$ total RNA were used to carry out PCR for TRAIL, with ready to use Gene Expression Product (Applied Biosystems) in a unique PCR master mix (Applied Biosystems). Quantitative PCR was developed on an ABI Prism 7700 Sequence Detector (Applied Biosystems). For each experiment, amplification of GAPDH cDNA was carried out simultaneously as an endogenous control of the total RNA quantity in the reaction. We incubated BM-DCs overnight with $1,000 \mathrm{U} / \mathrm{ml}$ of IFN- $\gamma$ (eBioscience) as a positive control of TRAIL mRNA expression (60).

Cytotoxicity assays. Human, rat, or mouse isolated DCs were mixed with target cells at different effector/target ratios in a 96-well plate in triplicates. After a 48-hour mixed culture, live tumor cells were revealed after a crystal violet incubation as previously reported (59). Caspase-dependent cytotoxicity was evaluated by adding Z-VAD-fmk to a final concentration of $100 \mu \mathrm{M}$ in wells. Mechanisms of TRAIL, Fas ligand, perforin, or NO-dependent cytotoxicity were appreciated by adding mouse neutralizing anti-

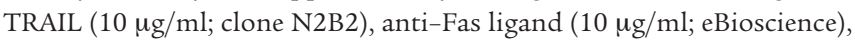
or isotype controls $(10 \mu \mathrm{g} / \mathrm{ml})$; human anti-TRAIL ( $50 \mathrm{ng} / \mathrm{ml}$; Abcam) or isotype control (50 ng/ml); and concanamycin A (100 nM; Sigma-Aldrich) or L-NMMA (1 mM; Sigma-Aldrich) in triplicate wells.

For the chromium release assay, cell cytotoxicity was measured in a standard 6 -hour ${ }^{51} \mathrm{Cr}$ release assay at $37^{\circ} \mathrm{C}$. Specific cytotoxicity was calculated as percentage ${ }^{51} \mathrm{Cr}$ release $=100 \times(\mathrm{cpm}$ experimental $-\mathrm{cpm}$ spontaneous release)/(cpm maximum release - cpm spontaneous release). For annexin $\mathrm{V} /$ 7-amino-actinomycin D (7-AAD) labeling, spontaneously detached cells or adherent cells collected after detachment with trypsin and EDTA were incubated 15 minutes with annexin V-PE (BD Biosciences - Pharmingen) at $20^{\circ} \mathrm{C}$, then stained 10 minutes with 7-AAD (BD Biosciences - Pharmingen), and then analyzed by flow cytometry.

Priming and vaccination by TIDCs. To study the capacity of TIDCs to prime $\mathrm{T}$ cells, $3 \times 10^{5}$ purified CD $11 \mathrm{~b}^{+}$TIDCs were injected into the footpad of mice and 5 days later draining popliteal lymph nodes were harvested, seeded in 96 U-well plates $\left(5 \times 10^{5}\right.$ cells per well), and restimulated with killed CT26 for 3 days before the collection of the supernatants. Rat TIDCs $\left(10^{5}\right.$ cells) were incubated 2 days with $10^{4}$ lymphocytes isolated from the spleen of rats immunized against killed PROb cells as previously described (18). IFN- $\gamma$ production was measured in the supernatants by ELISA (OptEIA ELISA Kit; BD Biosciences). The ability of TIDCs to immunize mice was studied by injecting $3 \times 10^{5} \mathrm{CD} 11 \mathrm{~b}^{+}$TIDCs into the footpads of mice and by challenging these animals 7 days later with $5 \times 10^{5} \mathrm{CT} 26$ cells. After 20 days, mice were challenged with the same amount of TS/A irrelevant syngeneic cells. Vaccination of rats was studied by injecting $5 \times 10^{5}$ TIDCs into footpads and by challenging these animals 7 days later with $10^{6} \mathrm{PROb}$ cells or G1V1A1 irrelevant syngeneic cells. 
Statistics. Statistical significance $(P<0.05, P<0.01)$ was determined by the 2-tailed Mann-Whitney's $U$ test or by Kruskal-Wallis test as appropriate.

\section{Acknowledgments}

We acknowledge Patrick Saulnier from the Translational Research Laboratory for all the technical advice he gave us for the development of quantitative RT-PCRs and Sophie Viaud for the preparation of J558 supernatant. We thank the Institut Gustave Roussy animal facility for help in breeding transgenic mice. We received grant support from Fondation pour la Recherche Médicale (to S. Roux and L. Apetoh), Association pour la Recherche contre le Cancer (to G. Mignot), and Institut National de la Santé et de la Recherche Médicale (to F. Ghiringhelli). This work was supported by special grants from the Ligue contre le Cancer de Bourgogne and the Association pour la Recherche contre le Cancer.

Received for publication April 9, 2008, and accepted in revised form August 20, 2008.

Address correspondence to: François Ghiringhelli, CRI INSERM 866, Faculté de Médecine, 21079 Dijon, France or Centre GeorgesFrancois Leclerc 1 rue du Professeur Marion, 21000 Dijon, France. Phone: 33-380-39-33-54; Fax: 33-380-39-34-34; E-mail: francois. ghiringhelli@yahoo.fr.

Stephan Roux and Lionel Apetoh contributed equally to this work.
1. Cai, X.Y., et al. 2006. Dendritic cell infiltration and prognosis of human hepatocellular carcinoma. J. Cancer Res. Clin. Oncol. 132:293-301.

2. Troy, A., Davidson, P., Atkinson, C., and Hart, D. 1998. Phenotypic characterisation of the dendritic cell infiltrate in prostate cancer. J. Urol. 160:214-219.

3. Nestle, F.O., Burg, G., Fah, J., Wrone-Smith, T., and Nickoloff, B.J. 1997. Human sunlight-induced basal-cell-carcinoma-associated dendritic cells are deficient in T cell co-stimulatory molecules and are impaired as antigen-presenting cells. Am. J. Pathol. 150:641-651.

4. Bergeron, A., El-Hage, F., Kambouchner, M., Lecossier, D., and Tazi, A. 2006. Characterisation of dendritic cell subsets in lung cancer micro-environments. Eur. Respir. J. 28:1170-1177.

5. Gerlini, G., et al. 2004. Metastatic melanoma secreted IL-10 down-regulates CD 1 molecules on dendritic cells in metastatic tumor lesions. Am. J. Pathol. 165:1853-1863.

6. Treilleux, I., et al. 2004. Dendritic cell infiltration and prognosis of early stage breast cancer. Clin. Cancer Res. 10:7466-7474.

7. Movassagh, M., et al. 2004. Selective accumulation of mature DC-Lamp+ dendritic cells in tumor sites is associated with efficient T-cell-mediated antitumor response and control of metastatic dissemination in melanoma. Cancer Res. 64:2192-2198.

8. Chaux, P., Hammann, A., Martin, F., and Martin, M. 1993. Surface phenotype and functions of tumorinfiltrating dendritic cells: CD8 expression by a cell subpopulation. Eur. J. Immunol. 23:2517-2525.

9. Chaux, P., Favre, N., Martin, M., and Martin, F. 1997. Tumor-infiltrating dendritic cells are defective in their antigen-presenting function and inducible B7 expression in rats. Int. J. Cancer. 72:619-624.

10. Vicari, A.P., et al. 2002. Reversal of tumor-induced dendritic cell paralysis by CPG immunostimulatory oligonucleotide and anti-interleukin 10 receptor antibody. J. Exp. Med. 196:541-549.

11. Guiducci, C., Vicari, A.P., Sangaletti, S., Trinchieri, G., and Colombo, M.P. 2005. Redirecting in vivo elicited tumor infiltrating macrophages and dendritic cells towards tumor rejection. Cancer Res. 65:3437-3446.

12. Preynat-Seauve, O., et al. 2006. Tumor-infiltrating dendritic cells are potent antigen-presenting cells able to activate $\mathrm{T}$ cells and mediate tumor rejection. J. Immunol. 176:61-67.

13. Gabrilovich, D. 2004. Mechanisms and functional significance of tumour-induced dendritic-cell defects. Nat. Rev. Immunol. 4:941-952.

14. Bell, D., et al. 1999. In breast carcinoma tissue, immature dendritic cells reside within the tumor, whereas mature dendritic cells are located in peritumoral areas. J. Exp. Med. 190:1417-1426.

15. Perrot, I., et al. 2007. Dendritic cells infiltrating human non-small cell lung cancer are blocked at immature stage. J. Immunol. 178:2763-2769.
16. Ghiringhelli, F., et al. 2005. Tumor cells convert immature myeloid dendritic cells into TGF-betasecreting cells inducing CD4+CD25+ regulatory T cell proliferation. J. Exp. Med. 202:919-929.

17. Curiel, T.J., et al. 2004. Specific recruitment of regulatory $T$ cells in ovarian carcinoma fosters immune privilege and predicts reduced survival. Nat. Med. 10:942-949.

18. Ghiringhelli, F., et al. 2004. CD4+CD25+ regulatory $\mathrm{T}$ cells suppress tumor immunity but are sensitive to cyclophosphamide which allows immunotherapy of established tumors to be curative. Eur. J. Immunol. 34:336-344.

19. Chen, M.L., et al. 2005. Regulatory T cells suppress tumor-specific CD8 $\mathrm{T}$ cell cytotoxicity through TGF-beta signals in vivo. Proc. Natl. Acad. Sci. U. S. A. 102:419-424

20. Ghiringhelli, F., et al. 2005. CD4+CD25+ regulatory $\mathrm{T}$ cells inhibit natural killer cell functions in a transforming growth factor-beta-dependent manner. J. Exp. Med. 202:1075-1085.

21. Tsuji, S., et al. 2000. Maturation of human dendritic cells by cell wall skeleton of Mycobacterium bovis bacillus Calmette-Guerin: involvement of toll-like receptors. Infect. Immun. 68:6883-6890.

22. Akazawa, T., et al. 2004. Adjuvant-mediated tumor regression and tumor-specific cytotoxic response are impaired in MyD88-deficient mice. Cancer Res. 64:757-764.

23. Taieb, J., et al. 2006. A novel dendritic cell subset involved in tumor immunosurveillance. Nat. Med. 12:214-219.

24. Chan, C.W., et al. 2006. Interferon-producing killer dendritic cells provide a link between innate and adaptive immunity. Nat. Med. 12:207-213.

25. Heldwein, K.A., et al. 2003. TLR2 and TLR4 serve distinct roles in the host immune response against Mycobacterium bovis BCG. J. Leukoc. Biol. 74:277-286.

26. von Meyenn, F., et al. 2006. Toll-like receptor 9 contributes to recognition of Mycobacterium bovis Bacillus Calmette-Guerin by Flt3-ligand generated dendritic cells. Immunobiology. 211:557-565.

27. Ghiringhelli, F., et al. 2007. Metronomic cyclophosphamide regimen selectively depletes CD4+CD25+ regulatory $\mathrm{T}$ cells and restores $\mathrm{T}$ and $\mathrm{NK}$ effector functions in end stage cancer patients. Cancer Immunol. Immunother. 56:641-648.

28. Lutsiak, M.E., et al. 2005. Inhibition of CD4(+)25+ $\mathrm{T}$ regulatory cell function implicated in enhanced immune response by low-dose cyclophosphamide. Blood. 105:2862-2868.

29. Lamm, D.L. 2000. Efficacy and safety of bacille Calmette-Guerin immunotherapy in superficial bladder cancer. Clin. Infect. Dis. 31(Suppl. 3):S86-S90.

30. Vermorken, J.B., et al. 1999. Active specific immunotherapy for stage II and stage III human colon cancer: a randomised trial. Lancet. 353:345-350.

31. Fricke, I., et al. 2006. Mycobacteria induce IFNgamma production in human dendritic cells via triggering of TLR2. J. Immunol. 176:5173-5182.

32. Kemp, T.J., et al. 2005. Neutrophil stimulation with Mycobacterium bovis bacillus Calmette-Guerin (BCG) results in the release of functional soluble TRAIL/Apo-2L. Blood. 106:3474-3482.

33. Ludwig, A.T., et al. 2004. Tumor necrosis factorrelated apoptosis-inducing ligand: a novel mechanism for Bacillus Calmette-Guerin-induced antitumor activity. Cancer Res. 64:3386-3390.

34. Stary, G., et al. 2007. Tumoricidal activity of TLR7/8-activated inflammatory dendritic cells. J. Exp. Med. 204:1441-1451.

35. Korthals, M., et al. 2007. Monocyte derived dendritic cells generated by IFN-alpha acquire mature dendritic and natural killer cell properties as shown by gene expression analysis. J. Transl. Med. 5:46.

36. Diehl, G.E., et al. 2004. TRAIL-R as a negative regulator of innate immune cell responses. Immunity. 21:877-889.

37. Taieb, J., et al. 2006. Chemoimmunotherapy of tumors: cyclophosphamide synergizes with exosome based vaccines. J. Immunol. 176:2722-2729.

38. Turk, M.J., et al. 2004. Concomitant tumor immunity to a poorly immunogenic melanoma is prevented by regulatory T cells. J. Exp. Med. 200:771-782.

39. Hori, S., Nomura, T., and Sakaguchi, S. 2003. Control of regulatory $\mathrm{T}$ cell development by the transcription factor Foxp3. Science. 299:1057-1061.

40. Kasprowicz, D.J., et al. 2005. Dynamic regulation of FoxP3 expression controls the balance between CD4+ T cell activation and cell death. Eur. J. Immunol. 35:3424-3432.

41. Schiavoni, G., et al. 2000. Cyclophosphamide induces type I interferon and augments the number of CD44(hi) T lymphocytes in mice: implications for strategies of chemoimmunotherapy of cancer. Blood. 95:2024-2030.

42. Ghiringhelli, F., Menard, C., Martin, F., and Zitvogel, L. 2006. The role of regulatory T cells in the control of natural killer cells: relevance during tumor progression. Immunol. Rev. 214:229-238.

43. Curiel, T.J. 2007. Tregs and rethinking cancer immunotherapy. J. Clin. Invest. 117:1167-1174.

44. Lee, J.C., Lee, K.M., Kim, D.W., and Heo, D.S. 2004. Elevated TGF-beta1 secretion and down-modulation of NKG2D underlies impaired NK cytotoxicity in cancer patients. J. Immunol. 172:7335-7340.

45. Ullrich, E., et al. 2008. Trans-presentation of IL-15 dictates IFN-producing killer dendritic cells effector functions. J. Immunol. 180:7887-7897.

46. Smyth, M.J., et al. 2006. CD4+CD25+ T regulatory cells suppress NK cell-mediated immunotherapy of cancer. J. Immunol. 176:1582-1587.

47. Wesa, A.K., and Storkus, W.J. 2008. Killer dendritic cells: mechanisms of action and therapeutic implications for cancer. Cell Death Differ. 15:51-57.

48. Ullrich, E., Chaput, N., and Zitvogel, L. 2008. Killer Dendritic cells and their potential role in immunotherapy. Horm. Metab. Res. 40:1-7.

49. Josien, R., Heslan, M., Soulillou, J.P., and Cuturi, 
M.C. 1997. Rat spleen dendritic cells express natural killer cell receptor protein 1 (NKR-P1) and have cytotoxic activity to select targets via a Ca2+-dependent mechanism. J. Exp. Med. 186:467-472.

50. Nicolas, A., et al. 2007. Dendritic cells trigger tumor cell death by a nitric oxide-dependent mechanism. J. Immunol. 179:812-818.

51. Shi, J., et al. 2005. Activated human umbilical cord blood dendritic cells kill tumor cells without damaging normal hematological progenitor cells. Cancer Sci. 96:127-133.

52. Manna, P.P., and Mohanakumar, T. 2002. Human dendritic cell mediated cytotoxicity against breast carcinoma cells in vitro. J. Leukoc. Biol. 72:312-320.

53. Blasius, A.L., Barchet, W., Cella, M., and Colonna,
M. 2007. Development and function of murine $\mathrm{B} 220+\mathrm{CD} 11 \mathrm{c}+\mathrm{NK} 1.1+$ cells identify them as a subset of NK cells. J. Exp. Med. 204:2561-2568.

54. Vosshenrich, C.A., et al. 2007. CD11cloB220+ interferon-producing killer dendritic cells are activated natural killer cells. J. Exp. Med. 204:2569-2578.

55. Caminschi, I., et al. 2007. Putative IKDCs are functionally and developmentally similar to natural killer cells, but not to dendritic cells. J. Exp. Med. 204:2579-2590.

56. Caignard, A., Martin, M.S., Michel, M.F., and Martin, F. 1985. Interaction between two cellular subpopulations of a rat colonic carcinoma when inoculated to the syngeneic host. Int. J. Cancer. 36:273-279.

57. Kayagaki, N., et al. 1999. Expression and function of
TNF-related apoptosis-inducing ligand on murine activated NK cells. J. Immunol. 163:1906-1913.

58. Barrat, F.J., et al. 2005. Nucleic acids of mammalian origin can act as endogenous ligands for Toll-like receptors and may promote systemic lupus erythematosus. J. Exp. Med. 202:1131-1139.

59. Bonnotte, B., et al. 2001. Identification of tumorinfiltrating macrophages as the killers of tumor cells after immunization in a rat model system. J. Immunol. 167:5077-5083.

60. Fanger, N.A., Maliszewski, C.R., Schooley, K., and Griffith, T.S. 1999. Human dendritic cells mediate cellular apoptosis via tumor necrosis factor-related apoptosis-inducing ligand (TRAIL). J. Exp. Med. 190:1155-1164. 